\title{
EFEITO DA UMIDADE NAS PROPRIEDADES FÍSICAS E ESTRUTURAIS DO BAGAÇO DE CANA
}

\author{
F. B. MENDES ${ }^{1}$, A.M. CHAUX ${ }^{1}$ J.C, THOMEO ${ }^{1}$ \\ Universidade Estadual Paulista - UNESP-IBILCE, Departamento de Engenharia de Alimentos \\ E-mail: $\underline{\text { fbm_ufu@yahoo.com.br, anachauxg@gmail.com }}$
}

RESUMO: Atualmente, o bagaço de cana é um dos resíduos agroindustriais de maior estudo. O interesse, em grande parte, se baseia em suas propriedades físicas, seu potencial calorífico e sua elevada disponibilidade. Ele é ainda considerado uma biomassa cujo valor agregado está relacionado à sua venda direta e também empregado como fonte de energia térmica e elétrica. $\mathrm{O}$ presente trabalho teve como objetivo estudar e estimar algumas propriedades físicas do bagaço de cana-de-açúcar como densidade aparente, densidade real, porosidade, relacionando a influência do fator umidade em torno destas propriedades. Os resultados demonstram que a umidade exerce um importante papel nas propriedades físicas e estruturais analisadas, uma vez que o bagaço, do ponto de vista macroscópico, é um material hidrofóbico formado por lignina, hemicelulose, e outros compostos orgânicos de cadeia longa. A partir do bagaço seco (7\% b.u) até o bagaço umidificado ( $86 \%$ b.u), a sua densidade real reduz pela metade. A porosidade do bagaço também reduz com o aumento da umidade. Os valores de porosidade foram comparados através de diferentes técnicas de análise.

Palavras-chave: umidade, bagaço de cana, propriedades físicas, propriedades estruturais.

\section{INTRODUÇÃO}

A produção mundial de cana de açúcar em 2011 foi de 1.500 MT de acordo com a FAO (2011), tendo o Brasil o primeiro lugar com uma produção anual de cerca de 600 MT de cana, o que corresponde a quase $40 \%$ da produção mundial. A cana-de-açúcar é um recurso agrícola utilizado predominantemente na produção de açúcar e etanol. O subproduto do seu processamento resulta numa biomassa a qual é utilizada na geração de energia térmica e elétrica para consumo na planta industrial e seu excedente para exportação (Rossell et al.,2012). No Brasil, a quantidade gerada de bagaço de cana a partir do seu processamento é de aproximadamente 160 milhões de toneladas (FAOSTAT), (CANTARELLA, 2009). Nos últimos anos, o bagaço, material lignocelulósico, tem sido estudado como matéria prima para os processos de hidrólise ácida ou enzimática (Antonio Bizzo, Lenço, Carvalho, \& Veiga, 2014) com intuito de obtenção do etanol celulósico. Do total de bagaço de cana gerado nas usinas sucroenergéticas, a maior parte é para consumo próprio na distribuição energética da planta industrial para a produção de açúcar e etanol. Em geral, permanece um excedente de bagaço de cerca de $20 \%$ do volume de bagaço produzido, permanecendo estocado no pátio de bagaço (UNICA, 2013). 
Dentre as possíveis aplicações do bagaço de cana citam-se: matéria-prima utilizada como fonte de energia para geração de energia elétrica; biomassa com potencial para aplicação em reaproveitamento energético (produção de plásticos, biocombustíveis, entre outros) e fonte de fibra para alimentação animal de bovinos.

Das aplicações citadas, a utilização do bagaço como fonte de energia tem maior predominância devido às suas vantagens econômicas e técnicas, em relação às demais aplicações. (BIZZO et. al, 2014). Como fonte energética, o bagaço separado na sua forma mais simples, é diretamente queimado nas caldeiras de alta pressão das usinas. Neste domínio, existem estudos para aumentar seu potencial energético otimizando sua combustão quando obtido na forma de pellets. O processo de peletização do bagaço consiste na redução da umidade do material abaixo de $10 \%$, aumentando seu potencial calorífico. Outra vantagem desta técnica seria a redução do seu volume, facilitando seu transporte, seu manuseio e estocagem (ERLICH et al.,2005).

O bagaço de cana tem sido utilizado também como substrato para obtenção de enzimas celulolíticas usadas em estudos para viabilizar a produção do etanol de segunda geração. Entretanto, os detalhes estruturais dos polímeros existentes no tecido da cana-de-açúcar, os quais são os potenciais substratos para estas enzimas, não foram estudadas com a mesma intensidade. É de grande importância desvendar a complexidade estrutural dos polímeros da parede celular, bem como as suas interações na parede, o que auxiliaria na resolução dos problemas de recalcitrância (DE SOUZA, 2013). Zanelato (2011) fez uso do princípio da Fermentação em Estado Sólido (FES) em leito fixo na obtenção de enzimas utilizando fungos filamentosos termófilos. A cinética de absorção de água pelo bagaço de cana e farelo de trigo a $45^{\circ} \mathrm{C}$ é fator que determina o crescimento do fungo e a produtividade das enzimas no processo fermentativo.

Teixeira et al. (2007) utilizaram bagaço de cana hidrolisado como suplemento na alimentação de bovinos tendo como resultado que até $40 \%$ em matéria seca é recomendável para obter ganhos de peso no animal. Portanto, nos últimos anos, o bagaço não só é um resíduo, senão uma fonte importante de energia e como matéria-prima para processos industriais o que faz que o conhecimento das suas propriedades físicas e químicas seja de grande importância para o uso eficiente nos diversos processos mencionados (BIZZO et al., 2014). O objetivo deste trabalho consiste em determinar o efeito da umidade sobre as propriedades físicas e estruturais do bagaço de cana.

\section{MATERIAIS E MÉTODOS}

Uma descrição esquemática do preparo das amostras bem como da realização das análises estão apresentadas a seguir.

\subsection{Material}

O bagaço de cana foi obtido da Usina Onda Verde localizada no município de mesmo nome, na região noroeste do estado de São Paulo. O bagaço obtido foi extraído de ternos de moenda e 
embebido com água condensada ao longo da etapa de Extração de açúcares. O material foi mantido em sacos de polipropileno de baixa densidade e estocado em câmara fria a $4^{\circ} \mathrm{C}$, ao abrigo de umidade e luz pelo tempo necessário para realização dos experimentos.

\subsection{Métodos de análise}

\section{$\underline{\text { Hidratação do material }}$}

O bagaço foi colocado em um recipiente de vidro com água destilada na proporção 2:8 suficiente para hidratar toda a massa de bagaço. O vidro contendo o material foi colocado em câmara incubadora B.O.D modelo MA 415 (fabricada no Brasil) à temperatura de $45^{\circ} \mathrm{C}$ durante $24 \mathrm{~h}$. O material foi posteriormente retirado e para iniciar o experimento parte do excesso de água foi retirado com 4 folhas de papel toalha, sem pressionar, colocados sobre o bagaço umedecido. A umidade é inicialmente determinada com auxílio da balança de umidade Ohaus modelo MB45.

\section{$\underline{\text { Secagem das amostras }}$}

O bagaço úmido foi secado numa estufa com renovação e circulação de ar marca MA 037 (fabricado no Brasil), a temperatura foi mantida a $45^{\circ} \mathrm{C} \pm 0,3$. As amostras foram retiradas a cada seis horas durante período de 24 horas.

\section{$\underline{\text { Microscopia da estrutura do bagaço de cana }}$}

A secagem de amostras de bagaço hidratado retiradas a cada 6 horas foram conservadas em fixador para historisina, que consiste em solução de glutaraldeído 4\%, e solução paraformol 4\%. Elas são desidratadas com solução de etanol de 50 a $100 \%$ e xilol. O processo de desidratação dura 5 dias. Posteriormente, a partir do bagaço in natura dois grupos foram definidos: material fibroso e cascas. Estes dois grupos foram separados manualmente do bagaço in natura. A seguir, o material foi colocado em parafina por duas vezes de forma a fixar o material. O material foi cortado em lâminas de $7 \mathrm{~mm}$ espessura com uso do equipamento de corte marca LEICA RM 2155. Por fim, as lâminas passam por processo de desparafinização com solução de xilol mergulhada por cerca de 30 minutos. Antes de analisar em microscópio, o material foi imerso em solução de hematoxilina e também em solução de eosina para gerar o contraste.

\section{Determinação de umidade}

Todos os valores de umidade foram determinados usando balança de determinação de umidade de luz infravermelha marca Ohaus MB45.

\subsection{Propriedades físicas}

a) Determinação do volume real e aparente: O volume aparente do bagaço-controle foi determinado colocando $10 \mathrm{~g}$ de bagaço numa proveta de $150 \mathrm{~mL}$ e seu volume ocupado foi medido segundo a quantidade de massa. Para o volume real do bagaço, foram utilizados $10 \mathrm{~g}$ do 
bagaço numa proveta de $150 \mathrm{ml}$ contendo tolueno até $100 \mathrm{~mL}$, depois foi feita a leitura do volume deslocado.

b) Porosidade: a porosidade do bagaço foi determinada utilizando o picnômetro por comparação de ar (Figura 1), no qual é disposto o bagaço em um dos cilindros do picnômetro; depois o picnômetro foi fechado. No cilindro em que não possui amostra (sem bagaço) insuflou-se ar

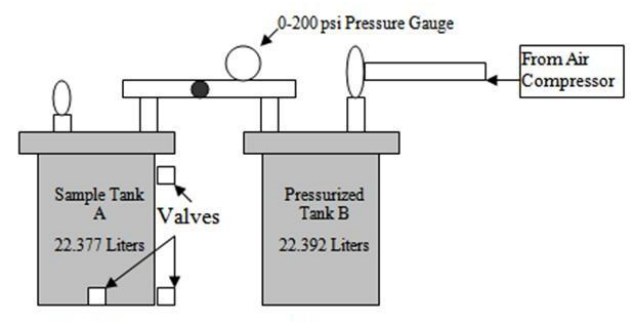

Figura 1: Picnômetro de comparação a ar

comprimido até que o valor da pressão no manômetro esteja fixa (P1). Em seguida, abriu-se a válvula de conexão entre os dois cilindros e aguardou que o valor da pressão indicada no manômetro se estabiliza-se para a leitura $(\mathrm{P} 2)$. O procedimento é feito em triplicata. O cálculo da porosidade é determinado seguindo a equação:

$$
P=1-\left(\frac{P 1}{P 2}\right)
$$

Adicionalmente, foi calculada a porosidade através da relação entre as densidades real e aparente de acordo com a equação (2) abaixo:

$$
P=1-\left(\frac{\rho \text { aparente }}{\rho \text { real }}\right)
$$

c) Propriedades estruturais: A estrutura do bagaço com diferentes conteúdos de umidade será analisada usando microscopia eletrônica de luz (MEL). O objetivo é verificar a diferença de intumescimento com água nas diferentes estruturas do bagaço de cana.

\section{RESULTADOS E DISCUSSÃO}

Para testar o grau de hidrofobicidade do bagaço e seu perfil de desidratação, o material foi deixado em estufa a $45^{\circ} \mathrm{C}$ com circulação de ar por 24 horas: 


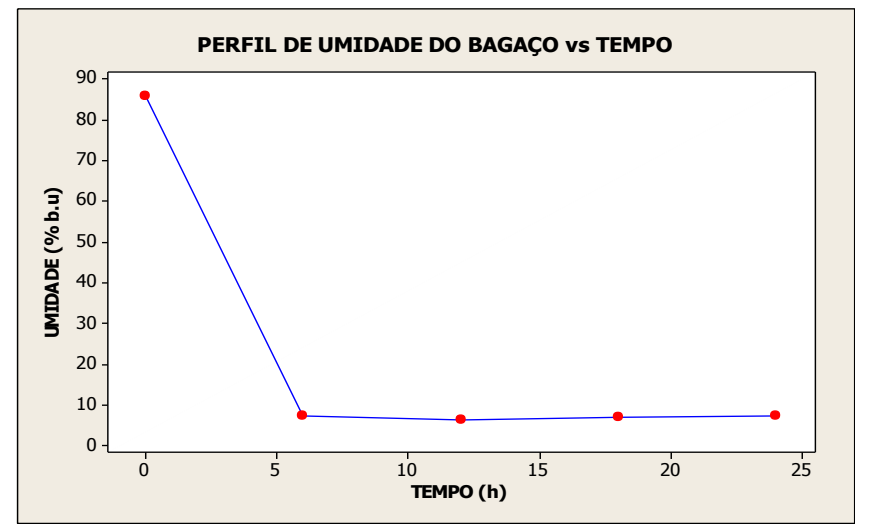

Figura 2: Perfil de umidade do bagaço após 24 horas de secagem

Observa-se que o processo de transferência de umidade do bagaço hidratado é extremamente rápido atingindo a umidade de equilíbrio dentro das seis primeiras horas.

Para determinação das propriedades físicas como densidade aparente, densidade real, os respectivos valores estão apresentados na Tabela 1 abaixo.

Tabela 1: Densidades real e aparente do bagaço de cana em diferentes graus de umidificação

\begin{tabular}{ccc}
\hline $\mathbf{X}$ & $\begin{array}{c}\boldsymbol{\rho} \text { Aparente } \\
\left(\mathbf{k g} / \mathbf{m}^{\mathbf{3}}\right)\end{array}$ & $\begin{array}{c}\boldsymbol{\rho} \text { Real } \\
\left(\mathbf{k g} / \mathbf{m}^{\mathbf{3}}\right)\end{array}$ \\
\hline 7,1 & 37,8 & 482,5 \\
30,4 & 66,8 & 515,5 \\
50,4 & 80,9 & 385,3 \\
67,6 & 125,2 & 410,7 \\
86,1 & 146,8 & 216,0 \\
\hline
\end{tabular}

Os dados do bagaço parcialmente seco $(30,4 \%$ b.u $)$ apresentaram desvio $\pm 4,2$ para a densidade aparente e para densidade real $\pm 56,9$. Para o bagaço de cana in natura, os valores de densidade aparente e densidade real tiveram desvios de $\pm 3,3$ e 42 respectivamente. Para o bagaço parcialmente hidratado, os desvios foram \pm 1 para densidade aparente e $\pm 75,6$ para densidade real. E por fim, para o bagaço hidratado $(86,1 \%$ b.u $)$, o desvio observado na densidade aparente foi de $\pm 0,4$ e para densidade real \pm 126 .

Os dados da densidade aparente obtidos com a umidade média de 50,4\% tem valores semelhantes aos obtidos por Rein et al. (2007), do qual pode-se inferir que as fibras que compõem o bagaço são fibras finas. Os dados da densidade real tem valores similares aos obtidos por Rasul et al (1999), no entanto é importante dizer que devido à porosidade das partículas e à natureza hidrofóbica do bagaço o procedimento utilizado pelo autor e no presente trabalho pode levar a não ter uma boa reprodutibilidade. $O$ conteúdo de umidade tem influência sobre a densidade real, como foi observado nos dados obtidos. Quanto mais úmido o bagaço, menor será sua densidade. Isto se deve ao fato de incorporar mais massa e, portanto o volume ocupado será maior. 
Tabela 2: Porosidade do bagaço em diferentes condições

\begin{tabular}{ccc}
\hline $\mathbf{X}$ & $\begin{array}{c}\text { Porosidade } \\
(\boldsymbol{\%})(\mathbf{E q . 2})\end{array}$ & $\begin{array}{c}\text { Porosidade } \\
(\boldsymbol{\%})(\mathbf{E q . 1})\end{array}$ \\
7,1 & 92,2 & 48,4 \\
50,4 & 78,8 & 48,6 \\
86,1 & 89,2 & 34,5 \\
\hline
\end{tabular}

Quanto à porosidade, pode-se dizer que para umidades mais altas a porosidade diminui. Neste caso, as partículas estão intumescidas de água, o que faz com que o espaço entre elas diminua, e estejam mais compactados. Os poros estão vazios e a entrada de ar é mais efetiva. $\mathrm{Na}$ literatura, os valores de porosidade com uma umidade intermediária, ao comparar os dados obtidos com os reportados por Alarcón et al., (2006) pode-se observar que são similares. Neste trabalho, foi realizada uma comparação entre a porosidade obtida pelo picnômetro de comparação de ar e a porosidade determinada como a razão entre as densidades aparente e real. Os dados mostraram diferenças nos valores, isto pode ser devido ao fato de que a determinação da densidade real foi feita pela submersão do bagaço em tolueno P.A, foi percebido visualmente que o bagaço sofre uma mudança da sua aparência em contato com o líquido, o que pode ser entendido como uma possibilidade de erro na metodologia de determinação do volume real. Poderia ser sugerido outro tipo de líquido para auxílio da medida de densidade real como, por exemplo, n-hexano, citado por Barrozo et al.,(2004).

As propriedades estruturais via microscopia de luz foi restringida devido à dificuldade de corte do material. O bagaço de cana, seja por seus componentes fibrosos, seja a sua casca que contém maior quantidade de lignina, apresenta grande dificuldade de serem fixados em parafina.

Recomenda-se o uso do procedimento de Microscopia de Varredura Eletrônica Ambiental (Environmental scanning electron microscopy - ESEM) para análise de biomateriais e sistemas biológicos. Este sistema permite a análise de materiais hidratados ou voláteis nas pressões de operação do equipamento de $\mathrm{MEV}$ ambiental sem a necessidade de recobrimento e sem a necessidade de preparação requerida para a técnica convencional (C-MEV), pois trabalha em baixo vácuo. (THOMAZ, E.C.S, 2012). É possível realizar a determinação de medidas de volume de intumescimento ou mesmo da porosidade de materiais fibrosos, assim como o bagaço de cana.

\section{CONSIDERAÇÕES FINAIS}

A heterogeneidade das partículas de bagaço e a porosidade este material dificulta a determinação precisa das suas propriedades físicas. Algumas tentativas de caracterização do tamanho de suas partículas através de peneiramento ou moagem podem auxiliar no entendimento de suas propriedades físicas discutidas neste trabalho, no entanto, encontrar-se-ia pouca aplicação industrial tais resultados uma vez que o bagaço de cana é obtido e manuseado em grandes volumes na indústria. Por outro lado, ressalta-se que o conhecimento destas propriedades físicas 
em função da umidade torna-se útil para o desenvolvimento de equipamentos e na melhor compreensão dos processos biotecnológicos.

\section{AGRADECIMENTOS}

Agradecemos ao professor Dr. Francisco Lopes, ao técnico Jesuíno ambos do Departamento de Engenharia de Alimentos e ao professor Dr. Sebastião Roberto Taboga do Departamento de Microscopia da faculdade de Biologia - UNESP. Agradecemos ao CNPq pelo apoio financeiro.

\section{REFERÊNCIAS}

ALARCÓN, Guillermo A. Roca; Caio Glauco Sanchez; Edgardo Olivares Gómez; Luís Augusto Barbosa Cortez. Caracterización del bagazo de la caña de azúcar. Parte I: características físicas. Ano 6. Enc. Energia. Meio Rural (2006).

CRANK, J. The mathematical of diffusion. 2 ed. Oxford: Clarendon Press, 1975. 414 p.

BIZZO, A, Lenço, P.C, Carvalho, D.J, Veiga, J.P.S. The generation of residual biomass during the production of bio-ethanol from sugarcane, its characterization and its use in energy production. Renewable and Sustainable Energy Reviews, 29, 589-603. doi:10.1016/j.rser.2013.08.056.

CANTARELLA, H. Instituto Agronômico de Campinas, IAC. Apresentação durante 1st. BrazilU.S Short Course of Biofuels. Julho, 2009.

ERLICH C, Öhman M, Björnbom E, Frasson T. Thermochemical characteristics of sugar cane bagasse pellets. Fuel, 2004; 84 (2005): 569-575.

FOOD AND AGRICULTURE ORGANIZATION OF THE UNITED NATIONS http://faostat.fao.org/site/339/default.aspx. Consulta em novembro de 2013.

RASUL, MG, RudolphV, Carsky M. Physical properties of bagasse. Fuel 1999;78:905-10.

REIN, P. Cane sugar engineering, Berlim: Verlag Dr. Albert Bartens KG, 2007; 768 p.

RIBEIRO, J.A., D.T. Oliveira, M.L. Passos, M.A.S. Barrozo. The use of nonlinearity measures to discriminate the equilibrium moisture equations for Bixa orellana seeds. Journal of Food Engineering 66 (2005) 63-68.

ROSSElL, J, Pradella G. C, Gómez E. O, Squina F. M. Physical Conditioning Unit of the Sugarcane Biomass Feedstock: Sugarcane Bagasse and Sugarcane Trash - PPDP1. Centro de Ciência e Tecnologia do Bioetanol - CTBE. Disponível em www.bioetanol.org.br. Consultado: novembro de 2013.

TEIXEIRA, F, Viera Aureliano, Nunes N. Bagaço de cana-de-açúcar na alimentação de bovinos. Revista electrónica de Veterinaria, 2007; 8 (6). 
ZANELATO, Alex. Produção de enzimas celulolíticas por fermentação em estado sólido em biorreator de leito fixo / Alex Izuka Zanelato. - São José do Rio Preto, SP - Brasil : [s.n.], 2011. Pg. 52-53.

DEMIRAY, E, Tulek Y. Drying characteristics of garlic (Allium sativum L) slices in a convective hot air dryer. Heat Mass Transfer 2013. DOI 10.1007/s00231-013-1286-9.

VIJAYARAJ B, Saravanan R, Renganarayanan S. Short communication Studies on thin layer drying of bagasse. Int. J. Energy Res 2007; 31:422-437.

MONSENIN, N.N. 1986. Physical Properties of Plant and Animal Materials. Gordon and Breach Science Publishers, New York.

DE SOUZA, Amanda. Leite, Débora. Pattahill, S. Hahn, Michael. Buckeridge, Marcos. Composition and Structure of Sugarcane Cell Wall Polysaccharides: Implications for SecondGeneration Bioethanol Production. Bioenergy Research. (2013) 6:564-579.

MORETTI, Márcia. Daniela Alonso Bocchini-Martins b, Christiane da Costa Carreira Nunes ,Maria Arévalo Villena, Olavo Micali Perrone, Roberto da Silva, Maurício Boscolo, Eleni Gomes. Pretreatment of sugarcane bagasse with microwaves irradiation and its effects on the structure and on enzymatic hydrolysis. Applied Energy 122 (2014) 189-195.

THOMAZ, E.C.S. Hidratação do cimento Portland - Microscopia Eletrônica Ambiental. Notas de Aula, Instituto Militar de Engenharia (IME). 2012. 